\title{
Seasonal variations of host resources influence foraging strategy in parasitoids
}

Delphine Eoche-Bosy ${ }^{1,2,3 *}$, Yannick Outreman ${ }^{2,4}$, Thiago Oliveira Andrade ${ }^{2,3,5}$, Liliane Krespi $^{2,5}$ \& Joan van Baaren ${ }^{2,3}$

${ }^{1}$ UMR 1349 IGEPP, INRA, F-35653 Le Rheu, France, ${ }^{2}$ Université Européenne de Bretagne, F-35000 Rennes, France, ${ }^{3}$ UMR 6553 ECOBIO, CNRS, Université de Rennes 1, F-35042 Rennes, France, ${ }^{4}$ UMR 1349 IGEPP, INRA, Agrocampus Ouest, F-35042 Rennes, France, and ${ }^{5}$ UMR 1349 IGEPP, INRA, Université de Rennes 1, F-35042 Rennes, France

*Correspondence: Delphine Eoche-Bosy, UMR 1349 IGEPP, INRA, Domaine de la Motte BP 35327, 35653 Le Rheu Cedex, France. E-mail: delphine.eoche-bosy@rennes.inra.fr

Running title: Seasonality of parasitoid foraging strategy

Key words: aphid parasitoids, generalist, opportunist, optimal foraging theory, specialist, switch, Hymenoptera, Aphididae, Hemiptera, cereal aphids, Braconidae, Aphidius spp.

Accepted: 2 May 2016 


\begin{abstract}
Many species have to cope with decreased resource availability and life expectancy during winter. The optimal foraging theory predicts that under these conditions, generalist foraging strategies should be favoured, via the acceptance of suboptimal resources. In contrast, during favourable seasons, specialist foraging strategies, i.e., a preferential consumption of the most profitable resources, should be favoured instead. Although spatial and fine-scale temporal dimensions of the influence of resource distribution on foraging strategies have long been studied in individual species, guild-level, large-scale temporal approaches (over multiple seasons) have rarely been considered. Parasitoids which can remain active during winter are an interesting model system which allows direct testing of resource profitability and reaching conclusions about foraging strategies from an evolutionary point of view. Here, we analysed how temporal variations of host resource availability in northwestern France impact the foraging strategies of parasitoid wasps. The foraging behaviours of dominant cereal aphid parasitoid species in relation to the two most abundant aphid host species were observed in winter and in spring. Because of a seasonal change in the host-parasitoid community and of a few species present in the fields each season, we were unable to confirm our hypothesis at the species level for all the studied species. Nevertheless, this study brought results consistent with our assumptions at the guild level, indicating that different species of a guild favour similar foraging strategies. In winter, female parasitoids generally adopted an opportunistic strategy, accepting all aphid hosts encountered, even if they were suboptimal. In spring, parasitoids displayed a specialist strategy by selecting preferentially a host species, but the better quality of preferentially-selected species remains to be fully demonstrated.
\end{abstract}




\section{Introduction}

Temperature strongly influences physiological mechanisms in ectotherms such as insects (Bale, 1996, 2002; Ramløv, 2000; Sinclair et al., 2003), and consequently conditions many behavioural strategies (Hance et al., 2007). Under temperate climates, some insects avoid unfavourable winter conditions by migrating or diapausing, whereas others endure them (Kimura \& Beppu, 1993; Polgár et al., 1995; Danks, 2005, 2006; Colinet et al., 2010). In addition to the climatic constraint, active organisms must also deal with another winter challenge: the resources essential for their survival are often less readily available (Danks, 2007). As searching for resources can generate high energetic costs, there is a positive selective pressure for appropriate strategies for habitat exploitation in order to optimize net energy gain. According to the optimal foraging theory (OFT) (MacArthur \& Pianka, 1966), this depends on the energy content of the resource, but also on other factors such as the rate at which the resource is encountered and the handling time (Bolnick et al., 2003). The selection of resource items should therefore correspond to an optimization of different factors, inducing potentially divergent strategies between seasons as resource density varies. Indeed, the OFT predicts that if the encounter rate with more profitable resources is low, suboptimal resources should always be accepted (Heller, 1980; Stephens \& Krebs, 1986). This prediction suggests that under winter conditions, organisms may enlarge their resource range, by being opportunistic through the exploitation of both optimal and suboptimal resources.

Surprisingly, although spatial (patches) and fine-scale temporal (minutes or hours) dimensions of the influence of resource distribution on foraging strategies have long been studied (Heller, 1980; Owen-Smith et al., 2010), large-scale temporal approaches (over multiple seasons) seem to have been more neglected. Only studies focusing precisely on one or few species, not necessarily insects, and aiming at studying their diet have been found to address the topic of seasonal resource availability (Sidorovich et al., 2008; Zhou et al., 2008; Clulow et al., 2011). These studies led to results that seem to follow OFT predictions, as they show foraging-strategy adjustments depending on the availability of resources (Riechert \& Harp, 1987; Wetherbee et al., 1990). For example, several studies on sharks revealed that many species show seasonal dietary shifts and fit the description of 'opportunistically selective feeders', i.e., they are selective when resources are abundant, and become more opportunistic when resource density decreases (Wetherbee et al., 1990). Similar results have been found in spiders (Riechert \& Harp, 1987), which present an unselective feeding behaviour most of the time, but become seasonally selective when prey are present in excess 
in the environment. However, in most of these studies, the biological model studied does not easily allow an assessment of the impact of resource profitability on an individual's fitness. It is therefore not possible to conclude from an evolutionary point of view that organisms are opportunistic because they feed on several suboptimal resources, and become selective when they feed on one or few types of resources which are more profitable in the environment.

Host-parasitoid interactions represent a unique case of dependence between fitness of an organism and its exploitation of food resources. The life cycle of parasitoids includes a free-living adult stage, during which females actively search for hosts on or in which to lay its eggs, and an immature stage, during which the larva develop inside or on the host, feeding (only) on host tissues and killing the host at the end of the its larval development (Godfray 1994). Due to this particular life history, the development of a parasitoid is intimately related to the quality of the selected and exploited host, which can depend on factors such as the species, development stage, size, or parasitic status of the host (Brodeur \& Boivin, 2004). There is therefore a direct link between the foraging behaviour of female parasitoids, i.e., their host choices, and the quality of the progeny produced, i.e., their fitness.

Aphid parasitoids are insects able to remain active during winter, provided winter conditions are sufficiently mild (Hance et al., 2007). Their winter persistence is made possible through the availability of hosts, which remain active as well. However, these host resources are scarce and highly patchily distributed. In addition, parasitoids have to face other environmental factors, such as a limited time horizon, because the mortality risk grows with the strong environmental stochasticity during winter (Roitberg et al., 1992), and a decrease of temperature and day duration that may restrict their activity, but also reduce competition. In these unfavourable winter conditions, the OFT suggests that female parasitoids should adopt an opportunistic strategy and always oviposit in the encountered hosts, regardless their profitability, whereas in spring, they should be more selective by choosing the host species with the highest profitability. The close link between female parasitoid fitness and host quality (Godfray, 1994) makes the assessment of host choice impact on female parasitoid fitness easier and direct. This makes parasitoid insects a choice model in this study, in which we investigate the hypothesis of a resource-exploitation switch according to resource seasonality by analysing host-selection strategies in multiple parasitoid species exploiting natural host populations.

The insect parasitoids of cereal aphids were considered in the present study. In winter, they can exploit anholocyclic aphid populations, which reproduce asexually throughout the year (Polgár et al., 1995; Dedryver et al., 2001). Host abundance reaches a seasonal peak in 
spring and summer, and then drastically declines in winter due to lower reproductive rates (Dixon, 1987; Krespi et al., 1997). We took into account in our experiments, at each season studied - winter and spring - the aphid parasitoids guild and their associated hosts found in cereal fields. We tested the two most abundant species each season to determine whether the same or different strategies would be observed in parasitoids undergoing the same evolutionary pressure. For each period, we studied (1) the host preference choice made by female parasitoids between the two most frequent aphid host species, and (2) the consequences of this host selection in terms of fitness (i.e., survival, developmental time, and size of offspring produced), in order to determine their performance in the host individuals selected. Our hypotheses were (1) winter parasitoids will display no preference, even if the various host species have different profitability values, and (2) if host species present different profitability values, then spring parasitoids will oviposit preferentially in the species resulting in the higher fitness.

\section{Materials and methods}

\section{Sampling and species studied}

Sampling was conducted in Brittany (northwestern France), where different parasitoid species are present in cereal crops throughout the year. In winter, Aphidius matricariae Haliday and Aphidius rhopalosiphi De Stefani-Perez (Hymenoptera: Braconidae, Aphidiinae) are the dominant species in the guild. In spring, A. rhopalosiphi remains numerous, but $A$. matricariae is not frequently found in cereal crops; other species, such as Aphidius avenae Haliday and Aphidius ervi Haliday, become more frequent (Krespi, 1990; Krespi et al., 1997; Andrade et al., 2013, 2015). Whereas A. matricariae, A. avenae, and A. ervi have been shown to exploit wide aphid host ranges, A. rhopalosiphi specializes in cereal aphid species (Starý, 1973). All these species are solitary pro-ovigenic koinobiont endoparasitoids which exclusively parasitize aphids.

Concerning aphid hosts, three species are common in cereal crops in the study site: Rhopalosiphum padi L., Sitobion avenae Fabricius, and Metopolophium dirhodum Walker (all Hemiptera: Aphididae) (Dedryver, 1987). Observations over the last decades indicate that during winter, population densities are very low, and $R$. padi is the dominant species in the aphid community, followed by S. avenae, then M. dirhodum, both being rare during winter (Krespi, 1990; Andrade et al., 2013). During spring, total aphid population densities increase, with $S$. avenae and $M$. dirhodum becoming the dominant species, whereas $R$. padi nearly 
disappears from the community in cereal fields (Krespi, 1990; Fievet et al., 2007). Aphid and parasitoid densities are low in winter, but parasitism rate can reach 38\% (Andrade et al., 2013). During spring, the density of aphids increases rapidly, and parasitism rates decrease accordingly (Andrade et al., 2015).

All experiments were done with parasitoid individuals collected from cereal fields at the immature stage in order to avoid any laboratory-induced alteration of foraging behaviour after some generations under rearing conditions. These experimental individuals have been collected in various cereal crops in the Long Term Ecological Research (LTER-Europe) site 'Armorique', around the city of Rennes, during both winter (in January and February) and spring (in April) in 2013. Within each field, the sampling sessions were performed during $1 \mathrm{~h}$ and all aphid mummies (i.e., dead aphids containing an immature parasitoid close to emergence) found were collected and placed individually in gelatine capsules $(1.5 \mathrm{~cm}$ long, $0.5 \mathrm{~cm}$ diameter) until parasitoid emergence. Parasitoid emergences were checked twice every day, at 9:00 and 18:00 hours. Newly-emerged parasitoids were identified based on morphological traits and for each species, individuals were placed together for $48 \mathrm{~h}$ in 'micro-cages' (9 cm long, $1.4 \mathrm{~cm}$ diameter) containing moistened cotton and droplets of honey to allow mating. Then females were collected for experiments and each female was tested only once.

In winter, 402 parasitoids emerged from sampled mummies, $42 \%$ were $A$. matricariae and 52\% were A. rhopalosiphi. These two most abundant species were therefore considered in our experiments (Table 1). In spring, 274 parasitoids emerged from sampled mummies and a change in community structure was observed: the two most abundant species were $A$. rhopalosiphi and A. avenae, with 17 and $81 \%$ relative abundance, respectively $(A$. matricariae individuals were no longer found) (Table 1).

Of the aphid community, $R$. padi and $S$. avenae were the two most frequent species found in crops in winter, $R$. padi being highly dominant (>90\% of the community) (Table 1). During spring, S. avenae and M. dirhodum were the most frequent species found (Table 1). During field samplings, at least 20 live aphids of each species available each season were also sampled. Each species was reared during only one generation in the laboratory on winter wheat (Triticum aestivum L. cv. Boston, Poaceae) in separated Plexiglas cages $(50 \times 50 \times 50$ $\mathrm{cm}$ ), after a quarantine period of 10 days in plastic tubes (16 cm long, $4 \mathrm{~cm}$ diameter) to ensure they were not parasitized, in order to produce host resources for the experiments. From these populations, only third instars were used for the experiments, as intermediate stages are known to be of better quality and usually preferred by female parasitoids (Colinet 
et al., 2005; Tahriri et al., 2007).

Maintenance of experimental individuals (aphids and parasitoids) and all experiments were done at $20 \pm 1{ }^{\circ} \mathrm{C}, 60 \pm 10 \%$ r.h., and L16: D8 photoperiod. We chose to standardize the experimental conditions used for both seasons, because the parasitoids are known to be active in the field only at the highest temperatures of the day in winter, which can exceed $20{ }^{\circ} \mathrm{C}$ where we sampled (Tougeron et al., 2016). The parasitoids used will have experienced more days in natural than in experimental conditions, as they were close to emergence at the time of collection of the mummies, and experiments were performed only few days after emergence.

\section{Seasonality of host preference}

For each season, the two most abundant aphid species were considered in experiments. The experimental setup consisted of introducing one aphid individual of each aphid species in a common 4-cm-diameter Petri dish, isolated on a piece of winter wheat leaf. A female parasitoid of a given species was then introduced in the arena. For each choice test, we recorded the (1) aphid species first encountered, in order to test whether parasitoid choice could be made from a distance (as already shown for A. ervi; Le Lann et al., 2011a), and (2) outcome of the encounter, i.e., host acceptance (ovipositor insertion) or host rejection (no ovipositor insertion). Female parasitoids were allowed to encounter only one aphid between both hosts presented. After each choice test, both aphids were replaced by two equivalent ones, until the female parasitoid had attacked a total of 20 aphids. At the end of each experiment, attacked aphids were isolated on winter wheat plantlets under rearing conditions, until their mummification. Each mummy was then isolated in a gelatine capsule until parasitoid emergence. For each season, 10 females of each parasitoid species were tested. Overall, 400 host choice tests were performed for each season. After attack of 20 hosts out of the aphids introduced into the arena, each female was put in Petri dishes with several aphids of both species during several minutes to allow them to parasitize more hosts, ensuring that a sufficient number of emerging offspring would be obtained for subsequent life-history-trait measurements. Aphids attacked were treated the same way as aphids from the choice experiment. In this experiment, absence of host preference does not mean absence of host discrimination. The host species are very different in size, colour, and defensive behaviour (alarm pheromones) (Dixon, 1987), and there is no doubt that parasitoid females are able to discriminate between aphid species (Le Ralec et al., 2005). 


\section{Seasonality of host performance}

Three life-history traits have been measured on the offspring emerging from all attacked aphids - parasitic success rate, development time, and hind tibia length -, which are common proxies used in the literature to describe the fitness of parasitoid individuals. Parasitic success rate is defined as the number of accepted aphids leading to emerging parasitoids divided by the total number of accepted aphids. Development time is the total time needed for the parasitoid offspring to develop from oviposition to adult emergence. It determines the generation time, which is inversely related to the growth rate of the parasitoid population (Tripathi \& Singh, 1990): a shorter development time could allow for a faster population growth. It could also contribute to reducing the predation pressure on parasitoids in mummies, a phase during which they are more vulnerable, according to the slow growth/high mortality hypothesis (Ishihara \& Ohgushi, 2006). Hind tibia length has been measured following the protocol used by Le Lann et al. (2011b). It is an indicator of the overall size and mass (Godfray, 1994), being positively correlated (Roitberg et al., 2001).

\section{Statistical analysis}

Host preference experiment. For each choice test, each female parasitoid was exposed to two aphid hosts of different species. The effect of host species on the probability of encounter by the parasitoid (i.e., aphid species choices) was analysed by a binomial non-parametric test (see details in Outreman et al., 2001). The null hypothesis was that the probability of encounter for a given aphid species was 0.5 (i.e., female parasitoids have no preference for a host species at distance). Once encountered, an aphid host was either accepted or rejected for oviposition. The effect of host species (i.e., fixed factor with two levels) on the acceptance rate was then analysed. In this experiment, several host individuals were attacked by the same female parasitoid. Then, the female parasitoid individual was considered as a random independent variable in statistical modelling. Generalized linear mixed models (GLMMs) were then fitted by assuming a binomial error and a logit-link function. All statistical modelling was performed by the 'Ime4' package in R v.3.0.2 (R Development Core Team, 2013).

Host performance experiment. The dependent variables studied were parasitic success rate, development time, and tibia size of the offspring. The effect of host species was tested on each dependent variable. In our experiments, several offspring originated from the same female parasitoid. The female parasitoid individual was then considered as a random 
independent variable in our statistical modelling. The effect of sex on offspring tibia size was also included in the models. GLMMs were fitted by assuming either a binomial, gamma, or Gaussian error according to the dependent variable and a logit or identity link function, respectively. To assess the significance of the individual model terms we used likelihood ratio tests.

\section{Results}

\section{Seasonality of host preference}

In winter, for the two parasitoid species studied, no significant differences were found for the encounter rate (binomial test, $A$. rhopalosiphi: $\mathrm{P}=0.60 ;$ A. matricariae: $\mathrm{P}=0.071$ ) nor for the host acceptance rate (GLMM, A. rhopalosiphi: $\chi^{2}=1.044, \mathrm{P}=0.31 ;$ A. matricariae: $\chi^{2}=$ $0.012, \mathrm{P}=0.91$, both d.f. $=1$ ) (Figure 1A). Thus, both A. matricariae and A. rhopalosiphi did not exhibit preference, neither remotely nor after contact, towards $R$. padi or S. avenae.

In spring, the two parasitoid species studied were not found to differ in encounter rate of $S$. avenae and $M$. dirhodum each being encountered half of the time (binomial test, $A$. rhopalosiphi: $\mathrm{P}=0.60 ;$ A avenae: $\mathrm{P}=0.071$ ) (Figure 1B). Thus, both parasitoids did not select their hosts from a distance. Both parasitoids displayed a significantly higher acceptance rate towards S. avenae (GLMM, A. rhopalosiphi: $\chi^{2}=44.668 ;$ A. avenae: $\chi^{2}=67.790$, both d.f. $=1, \mathrm{P}<0.001)($ Figure 1$)$.

\section{Seasonality of host performance}

In winter, the parasitic success rate of the two parasitoid species was not different between $S$. avenae and R. padi (GLMM, A. rhopalosiphi: $\chi^{2}=0.004, \mathrm{P}=0.95 ;$ A. matricariae: $\chi^{2}=$ $0.131, \mathrm{P}=0.72$, both d.f. $=1$ ) (Figure 2A). Aphidius rhopalosiphi showed a parasitic success rate of $37.7 \pm 3.7 \%$ in $S$. avenae and $35.5 \pm 3.7 \%$ in $R$. padi, whereas A. matricariae showed a parasitic success rate of $35.5 \pm 3.7 \%$ in $S$. avenae and $34.8 \pm 3.6 \%$ in $R$. padi. However, both parasitoids developed faster on $S$. avenae (A. rhopalosiphi: $\chi^{2}=12.032, \mathrm{P}<0.001 ; A$. matricariae: $\chi^{2}=4.9313, \mathrm{P}=0.026$, both d.f. $\left.=1\right)$ and had longer hind tibia $\left(\chi^{2}=16.856\right.$ and 14.771, respectively, both d.f. $=1, \mathrm{P}<0.001$ ) (Figures $2 \mathrm{~B}$ and C). In winter, $S$. avenae hosts resulted in larger parasitoids than $R$. padi and faster parasitoid development, with the same parasitism success. The size of the offspring produced by the winter parasitoid wasps was not affected by their sex (A. rhopalosiphi: $\chi^{2}=3.124, \mathrm{P}=0.077 ;$ A. matricariae $: \chi^{2}=0.460, \mathrm{P}=$ 0.50 , both d.f. $=1)$. 
In spring, as in winter, the two aphids had no specific effect on the parasitic success rate of A. rhopalosiphi: $46.3 \pm 3.8 \%$ in $S$. avenae and $55.5 \pm 4.4 \%$ in M. dirhodum (GLMM, $\chi^{2}=0.0261$, d.f. $=1, \mathrm{P}=0.87$ ) (Figure 3A). However, aphid species did affect the parasitism success of A. avenae: $38.7 \pm 3.9 \%$ in $S$. avenae vs. $23.4 \pm 4.1 \%$ in $M$. dirhodum $\left(\chi^{2}=6.803\right.$, d.f. $=1, \mathrm{P}=0.009)($ Figure $3 \mathrm{~A})$. Aphid host species had no effect on development time of $A$. rhopalosiphi $\left(\chi^{2}=1.1236\right.$, d.f. $\left.=1, \mathrm{P}=0.29\right)$, whereas development of $A$. avenae was significantly slower in $S$. avenae $\left(\chi^{2}=4.6567\right.$, d.f. $\left.=1, \mathrm{P}=0.030\right)$ (Figure 3B). Aphid host species had no effect on hind tibia length of either parasitoid (A. rhopalosiphi: $\chi^{2}=0.001, \mathrm{P}=$ $0.98 ;$ A. avenae: $\chi^{2}=0.939, \mathrm{P}=0.33$, both d.f. $=1$ ) (Figure 3C). The size of the offspring produced by the spring parasitic wasps depended on their sex (A. rhopalosiphi: $\chi^{2}=4.580, \mathrm{P}$ $=0.032 ;$ A. avenae: $\chi^{2}=13.219, \mathrm{P}<0.001$, both d.f. $\left.=1\right)$.

\section{Discussion}

Our results indicate that winter and spring female parasitoids show contrasting reactions when confronted with hosts. In winter, the two most abundant species in the parasitoid guild, A. matricariae and A. rhopalosiphi, when exposed to the dominant aphid hosts available, $R$. padi and S. avenae, did not express any preference for the host resources, exploiting both host species equally, as predicted. This absence of preference would not be associated with a lack of host species discrimination by parasitic wasps, as $S$. avenae and $R$. padi are highly different in terms of morphology, colour, and behaviour (Dixon, 1987). In spring, the two most frequent parasitoid species, A. avenae and A. rhopalosiphi, showed a preference towards the same aphid species, S. avenae. However, to evaluate the adaptive value of these contrasted foraging strategies by female parasitoids, it is necessary to link host species selection to host profitability in terms of offspring quality. In winter, it appears that S. avenae was a host of better quality than $R$. padi for both parasitoid species. Although both aphid species led to an equivalent parasitic success rate, development time was shorter and offspring tibia length larger in S. avenae. As expected, during the harsh winter season the two major parasitoid species of the guild are opportunistic, exploiting all host species available regardless of their quality. As predicted, the spring female parasitoids expressed a selective behaviour with regards to the available resources and this strategy could be related to host resources profitability: A. avenae prefers to parasitize $S$. avenae, which appears to be a host of better quality than $M$. dirhodum. Indeed, S. avenae allows a shorter development time and also leads to a higher parasitic success rate than M. dirhodum. Females of the second most 
frequent species in the parasitoid guild, A. rhopalosiphi, preferred to oviposit in one aphid species rather than the other, yet a better performance in the preferred aphid species has not been detected. Perhaps a difference in host quality was not necessarily reflected by the traits considered here, and concerns potentially other trait(s). For example, longevity, lipid reserves at emergence, and fecundity (estimated as the number of eggs contained in ovarioles) have not been considered. Another explanation would be that the more profitable host could also be more easily accessible under field conditions because, e.g., the host expresses less defensive behaviour or is easier to find in the environment ( $S$. avenae is known to be more present on wheat heads whereas $M$. dirhodum is more often hidden on leaves).

The present study suggests that the optimal host acceptance strategy in parasitoids may depend on the host resources seasonality. These results are consistent with those of Roitberg et al. (1992), who also found that female parasitoids show variable foraging strategies according to the season. Females of the Drosophila spp. parasitoid Leptopilina heterotoma (Thomson) generally reject hosts that are already parasitized, as they are considered to be poor hosts. However, Roitberg et al. (1992) showed that superparasitism (parasitism of a host by more than one individual of a single species) rate increases in females reared under autumn conditions, i.e., when individuals have a short life expectancy and therefore when time available for searching becomes limited, as is the case in winter for cereal aphid parasitoids. Nonetheless, this study considered the same host species and focused on the impact of the host parasitic status on the parasitoid foraging strategy.

Two out of the three parasitoid species studied were only present during one season: A. matricariae during winter and A. avenae during spring. Due to this seasonal change in the parasitoid guild, our study is not a strong test of our hypotheses even if our results are consistent with these assumptions. Even if no global switch of foraging strategies can be demonstrated here, our results indicate that the winter parasitoid guild did not exhibit any host preference, whereas in spring host species specialization could be generally favourable considering the higher host density. In addition, A. rhopalosiphi, the common species between the winter and the spring guild, displayed contrasting foraging strategies depending on the season. The adequacy of the host acceptance strategy to the ecological conditions can be achieved in two ways: balanced polymorphism (i.e., genotypes in the parasitoid population differ with time; some genotypes are frequent in winter and decline in spring) or phenotypic plasticity (i.e., the ability of one genotype to develop different phenotypes in different environments). To our knowledge, polymorphism in host acceptance strategy in parasitoids has not yet been demonstrated. Conversely, some experimental studies have demonstrated 
that wasps could change their host acceptance strategy in response to current environmental conditions experienced (Godfray, 1994; Babendreier \& Hoffmeister, 2002; Goubault et al., 2004; Outreman et al., 2005). Further investigations are therefore needed to exlain this strategy change.

Aphid parasitoids are of great importance in biological control against cereal aphids, which are serious crop pests in temperate regions (Schmidt et al., 2003). They represent an alternative or complementary control method to insecticides, which can be harmful to the environment and to human health. It is therefore essential to understand the interactions between aphid parasitoids and their hosts, and this study contributes to the comprehension of the seasonal dynamics of these interactions. Moreover, aphid-parasitoid systems have scarcely been studied in winter, because of sampling difficulties and low densities, despite the importance of parasitoids for the biological control of spring pest populations (Plantegenest et al., 2001). Indeed, winter is a crucial season for aphid population dynamics and therefore for the occurrence of spring outbreaks. The results of this study suggest that, as aphid parasitoids do not exhibit any host preference between aphid species in winter and attack all encountered aphids, they are potentially of use during winter for pest control in cereal crops.

\section{Acknowledgements}

This work was supported by the French National Research Agency Landscaphid program (grant number ANR-09-STRA-05) and by 'Région Bretagne'. All field and laboratory work conducted in this study comply with French legal code requirements. We are grateful to Philippe Louâpre, Lucy Alford, Franck Hieronimus, Philippe Vernon, and Josselin Montarry for the technical support provided and the comments on an earlier version of the manuscript. Special thanks to Stéphanie Llopis for the technical support provided for the aphids rearing.

\section{References}

Andrade TO, Hervé M, Outreman Y, Krespi L \& van Baaren J (2013) Winter host exploitation influences fitness traits in a parasitoid. Entomologia Experimentalis et Applicata 147: 167-174.

Andrade TO, Outreman Y, Krespi L, Plantegenest M, Vialatte A et al. (2015) Spatiotemporal variations in aphid-parasitoid relative abundance patterns and food webs in agricultural ecosystems. Ecosphere 6: 113 
Babendreier D \& Hoffmeister TS (2002) Superparasitism in the solitary ectoparasitoid Aptesis nigrocincta: the influence of egg load and host encounter rate. Entomologia Experimentalis et Applicata 105: 63-69.

Bale JS (1996) Insect cold hardiness: a matter of life and death. European Journal of Entomology 96: 369-382.

Bale JS (2002) Insects and low temperatures: from molecular biology to distributions and abundance. Philosophical Transactions of the Royal Society B 357: 849-862.

Bolnick DI, Svanbäck R, Fordyce JA, Yang LH, Davis JM et al. (2003) The ecology of individuals: incidence and implications of individual specialization. American Naturalist 161: 1-28.

Brodeur J \& Boivin G (2004) Functional ecology of immature parasitoids. Annual Review of Entomology 49: 27-49.

Clulow S, Peters KL, Blundell AT \& Kavanagh RP (2011) Resource predictability and foraging behavior facilitate shifts between nomadism and residency in the eastern grass owl. Journal of Zoology 284: 294-299.

Colinet H, Muratori F \& Hance T (2010) Cold-induced expression of diapause in Praon volucre: fitness cost and morpho-physiological characterization. Physiological Entomology 35: 301-307.

Colinet H, Salin C, Boivin G \& Hance T (2005) Host age and fitness-related traits in a koinobiont aphid parasitoid. Ecological Entomology 30: 473-479.

Danks HV (2005) Key themes in the study of seasonal adaptations in insects I. Patterns of cold hardiness. Applied Entomology and Zoology 40: 199-211.

Danks HV (2006) Key themes in the study of seasonal adaptations in insects II. Life-cycle patterns. Applied Entomology and Zoology 41: 1-13.

Danks HV (2007) The elements of seasonal adaptations in insects. Canadian Entomologist 139: 1-44.

Dedryver CA (1987) Biologie, Écologie et Dynamique des Populations de Pucerons des Céréales en Climat Océanique. PhD Dissertation, University of Paris XI, Paris, France.

Dedryver CA, Hullé M, Le Gallic JF, Caillaud M \& Simon JC (2001) Coexistence in space and time of sexual and asexual populations of the cereal aphid Sitobion avenae. Oecologia 128: $379-388$.

Dixon AFG (1987) Parthenogenetic reproduction and the rate of increase in aphids. Aphids: Their Biology, Natural Enemies and Control (ed. by AK Minks \& P Harrewijn), pp. 269287. Elsevier, Amsterdam, The Netherlands. 
Fievet V, Dedryver CA, Plantegenest M, Simon JC \& Outreman Y (2007) Aphid colony turnover influences the spatial distribution of the grain aphid Sitobion avenae over the wheat growing season. Agricultural and Forest Entomology 9: 125-134.

Godfray HJC (1994) Parasitoids: Behavioral and Evolutionary Ecology. Princeton University Press, Princeton, NJ, USA.

Goubault M, Fourrier J, Krespi L, Poinsot D \& Cortesero AM (2004) Selection strategies of parasitized hosts in a generalist parasitoid depend on patch quality but also on host size. Journal of Insect Behavior 17: 99-113.

Hance T, van Baaren J, Vernon P \& Boivin G (2007) Impact of extreme temperatures on parasitoids in a climate change perspective. Annual Review of Entomology 52: 107-126.

Heller R (1980) On optimal diet in a patchy environment. Theoretical Population Biology 17: 201-214.

Kimura MT \& Beppu K (1993) Climatic adaptations in the Drosophila immigrans species group: seasonal migration and thermal tolerance. Ecological Entomology 18: 141-149.

Krespi L (1990) Étude de la Biocénose Parasitaire des Pucerons des Céréales dans le Bassin de Rennes: Cas Particulier d'Aphidius uzbekistanicus Luz. PhD Dissertation, University of Rennes 1, Rennes, France.

Krespi L, Dedryver CA, Creach V, Rabasse JM, Le Ralec A \& Nénon JP (1997) Variability in the development of cereal aphid parasitoids and hyperparasitoids in oceanic regions as a response to climate and abundance of hosts. Environmental Entomology 26: 545-551.

Ishihara M \& Ohgushi T (2006) Reproductive inactivity and prolonged developmental time induced by seasonal decline in host plant quality in the willow leaf beetle Plagiodera versicolora (Coleoptera: Chrysomelidae). Environmental Entomology 35: 524-530.

Le Lann C, Outreman Y, van Alphen JJM \& van Baaren J (2011a) First in, last out: asymmetric competition influences patch exploitation of a parasitoid. Behavioral Ecology 22:101-107.

Le Lann C, Wardziak T, van Baaren J \& van Alphen JJM (2011b) Thermal plasticity of metabolic rates linked to life-history traits and foraging behavior in a parasitic wasp. Functional Ecology 25: 641-651.

Le Ralec A, Curty C \& Wajnberg E (2005) Inter-specific variation in the reactive distance of different aphid-parasitoid associations: analysis from automatic tracking of the walking path. Applied Entomology and Zoology 40: 413-420.

MacArthur RH \& Pianka ER (1966) On optimal use of a patchy environment. American Naturalist 100: 603-609. 
Outreman Y, Le Ralec A, Wajnberg E \& Pierre JS (2001) Can imperfect host discrimination explain partial patch exploitation in parasitoids? Ecological Entomology 26: 271-280.

Outreman Y, Le Ralec A, Wajnberg E \& Pierre JS (2005) Effects of within- and among-patch experiences on the patch-leaving decision rules in an insect parasitoid. Behavioral Ecology and Sociobiology 58: 208-217.

Owen-Smith N, Fryxell JM \& Merril EH (2010) Foraging theory upscaled: the behavioural ecology of herbivore movement. Philosophical Transactions of the Royal Society B 365: 2267-2278.

Polgár LA, Darvas B \& Völk1 W (1995) Induction of dormancy in aphid parasitoids: implications for enhancing their field effectiveness. Agriculture, Ecosystems and Environment 52: 19-23.

Plantegenest M, Pierre JS, Dedryver CA \& Kindlmann P (2001) Assessment of the relative impact of different natural enemies on population dynamics of the grain aphid Sitobion avenae in the field. Ecological Entomology 26: 404-410.

R Development Core Team (2013) R: A Language and Environment for Statistical Computing. R Foundation for Statistical Computing, Vienna, Austria.

Ramløv H (2000) Aspects of natural cold tolerance in ectothermic animals. Human Reproduction 15: 26-46.

Riechert S \& Harp J (1987) Nutritional ecology of spiders. Nutritional Ecology of Insects, Mites, Spiders and Related Invertebrates (ed. by F Slansky \& J Rodriguez), pp. 645-672. Wiley, New York, NY, USA.

Roitberg BD, Boivin G \& Vet LEM (2001) Fitness, parasitoids, and biological control: an opinion. Canadian Entomologist 133: 429-438.

Roitberg BD, Mangel M, Lalonde RG, Roitberg CA, van Alphen JJM \& Vet LEM (1992) Seasonal dynamic shifts in patch exploitation by parasitic wasps. Behavioral Ecology 3: 156-165.

Schmidt MH, Lauer A, Purtauf T, Thies C, Schaefer M \& Tscharntke T (2003) Relative importance of predators and parasitoids for cereal aphid control. Proceedings of the Royal Society of London B 270: 1905-1909.

Sidorovich VE, Solovej IA, Sidorovich AA \& Dyman AA (2008) Seasonal and annual variation in the diet of the raccoon dog Nyctereutes procyonoides in northern Belarus: the role of habitat type and family group. Acta Theriologica 53: 27-38.

Sinclair BJ, Vernon P, Klok CJ \& Chown SL (2003) Insects at low temperatures: an ecological perspective. Trends in Ecology and Evolution 18: 257-262. 
Starý P (1973) A review of the Aphidius species (Hymenoptera: Aphidiidae) of Europe. Annotationes Zoologicae et Botanicae 84: 1-85.

Stephens DW \& Krebs JR (1986) Foraging Theory. Princeton University Press, Princeton, NJ, USA.

Tahriri S, Talebi AA, Fathipour Y \& Zamani AA (2007) Host stage preference, functional response and mutual interference on Aphidius matricariae (Hym.: Braconidae: Aphidiinae) on Aphis fabae (Hom.: Aphididae). Entomological Science 10: 323-331.

Tougeron K, van Baaren J, Burel F \& Alford L (2016) Comparing thermal tolerance across contrasting landscapes: first steps towards understanding how landscape management could modify ectotherm thermal tolerance. Insect Conservation and Diversity 9: 171-180.

Tripathi RN \& Singh R (1990) Fecundity, reproductive rate, longevity, and intrinsic rate of increase of an aphidiid parasitoid Lysiphlebia mirzai. Entomophaga 35: 601-610.

Wetherbee BM, Gruber SH \& Cortes E (1990) Diet, feeding habits, digestion, and consumption in sharks, with special reference to the lemon shark, Negaprion brevirostris. Elasmobranchs as Living Resources: Advances in the Biology, Ecology, Systematics, and the Status of the Fisheries (ed. by HL Pratt Jr, SH Gruber \& T Taniuchi), pp. 29-47. NOAA Fisheries Technical Reports 90, United States National Marines Fishery Service, Silver Spring, MD, USA.

Zhou Y, Zhang J, Slade E, Zhang L, Palomares F et al. (2008) Dietary shifts in relation to fruit availability among masked palm civets (Paguma larvata) in central China. Journal of Mammalogy 89: 435-447.

\section{Figure captions}

Figure 1 Mean $( \pm \mathrm{SE} ; \mathrm{n}=10)$ relative host encounter and acceptance rate in $(\mathrm{A})$ winter (Aphidius rhopalosiphi and A. matricariae were exposed to aphid species Sitobion avenae and Rhopalosiphum padi) and (B) spring (A. rhopalosiphi and A. avenae were exposed to $S$. avenae and Metopolophium dirhodum). Asterisks indicate significant differences $(* * * \mathrm{P}<0.001 ; \mathrm{ns}$, not significant).

Figure 2 Influence of host species (Sitobion avenae and Rhopalosiphum padi) on mean ( \pm SE) (A) parasitic success rate [number of attacked aphids (ovipositor inserted) leading to emerged parasitoids divided by the total number of aphids attacked, \%], (B) development time (days), and (C) hind tibia length ( $\mathrm{mm}$ ) of males (M) and females (F) of the two 
parasitoids species, Aphidius rhopalosiphi and A. matricariae, in winter. Asterisks indicate significant differences $(* 0.01<\mathrm{P}<0.05, * * * \mathrm{P}<0.001$; ns, non-significant). Means are based on $38 \mathrm{M}$ and $23 \mathrm{~F}$ A. rhopalosiphi on S. avenae, $25 \mathrm{M}$ and $33 \mathrm{~F}$ A. rhopalosiphi on $R$. padi, $33 \mathrm{M}$ and $27 \mathrm{~F}$ A. matricariae on S. avenae, and $30 \mathrm{M}$ and $28 \mathrm{~F}$ A. matricariae on $R$. padi.

Figure 3 Influence of host species (Sitobion avenae and Metopolophium dirhodum) on mean ( \pm SE) (A) parasitic success rate [number of attacked aphids (ovipositor inserted) leading to emerged parasitoids divided by the total number of aphids attacked, \%], (B) development time (days), and (C) hind tibia length (mm) of males (M) and females (F) of the two parasitoids species, Aphidius rhopalosiphi and A. avenae in spring. Asterisks indicate significant differences $(* 0.01<\mathrm{P}<0.05$, $* * \mathrm{P}<0.01$; ns, non-significant). Means are based on 72 $\mathrm{M}$ and $8 \mathrm{~F}$ A. rhopalosiphi on S. avenae, $41 \mathrm{M}$ and $8 \mathrm{~F}$ A. rhopalosiphi on M. dirhodum, 52 $\mathrm{M}$ and $6 \mathrm{~F} \mathrm{~A}$. avenae on S. avenae, and $21 \mathrm{M}$ and $3 \mathrm{~F}$ A. avenae on M. dirhodum. 
Figure 1

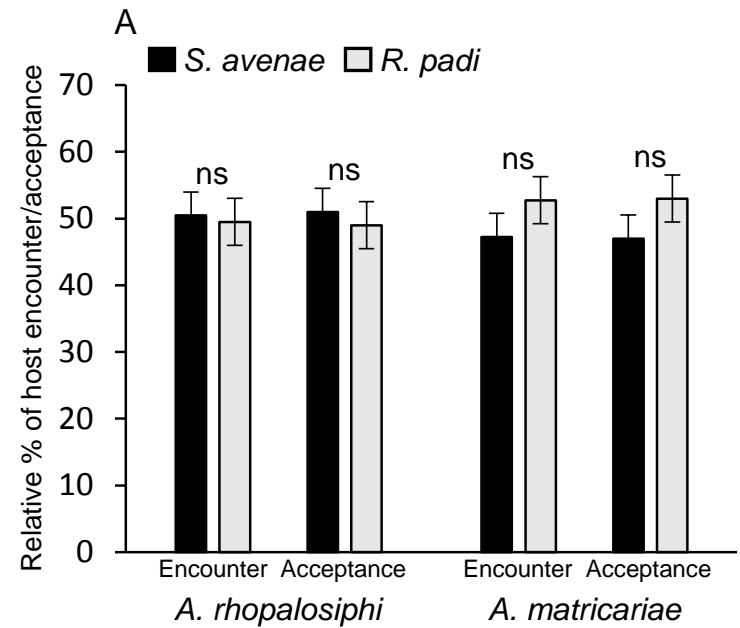

B

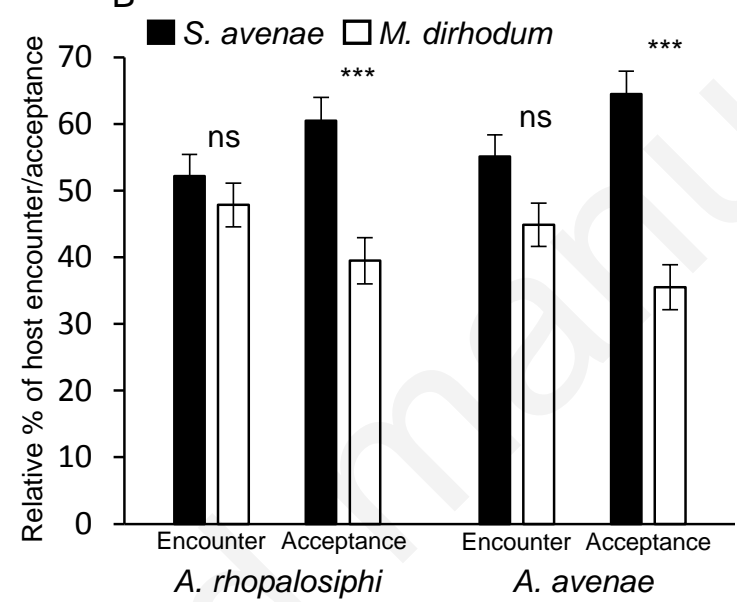


Figure 2

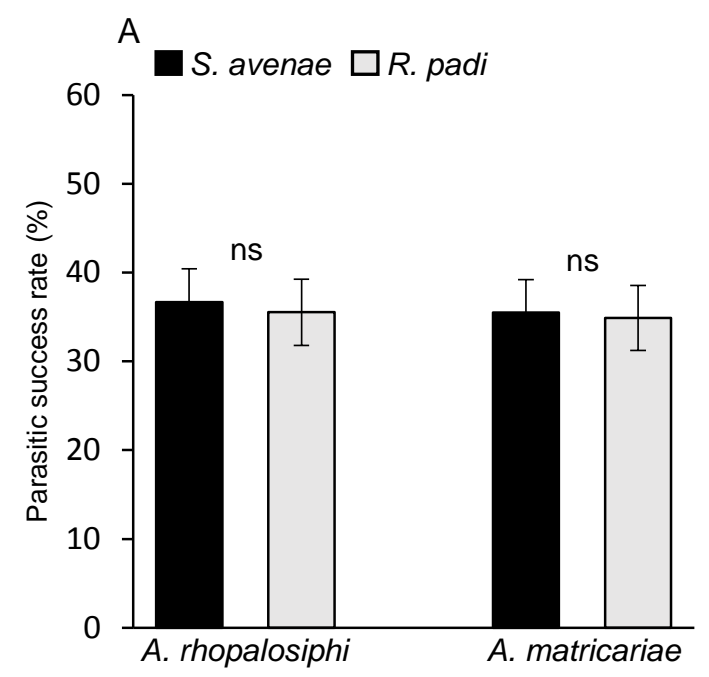

B

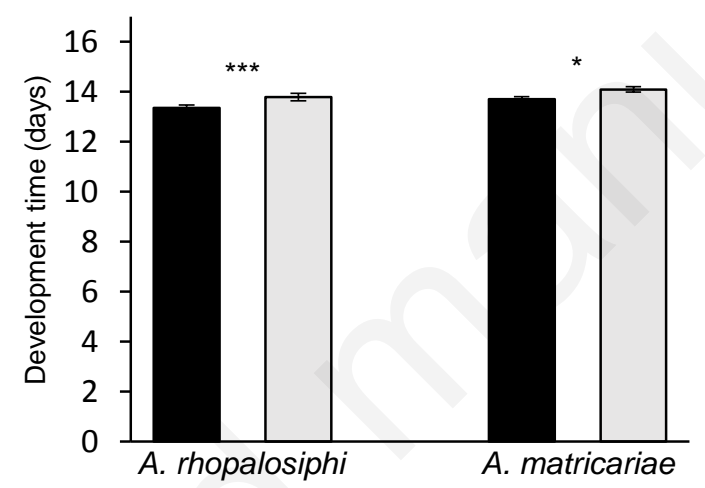

C

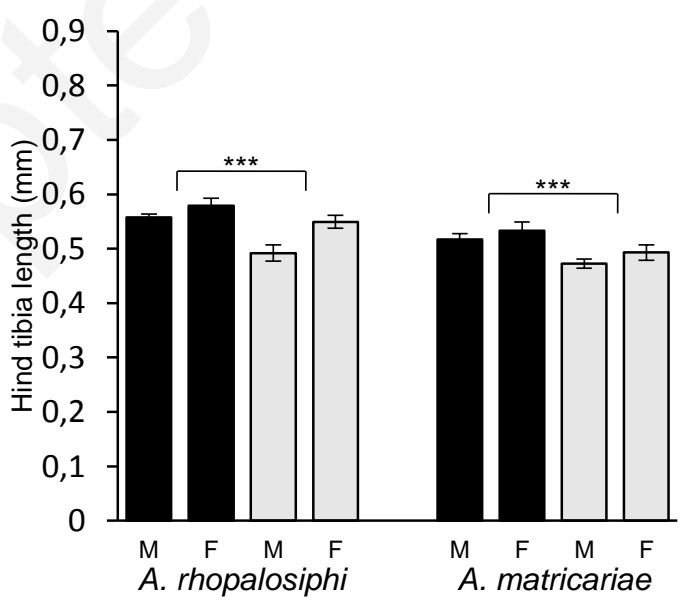


Figure 3
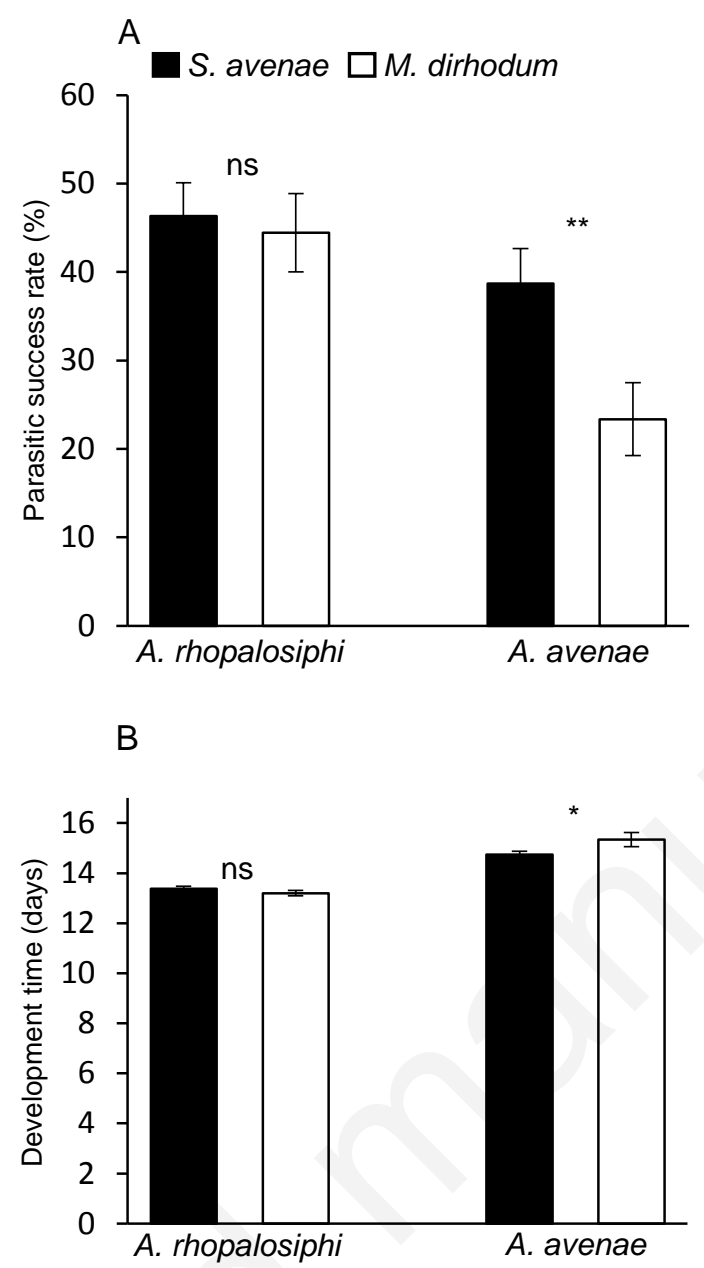

C

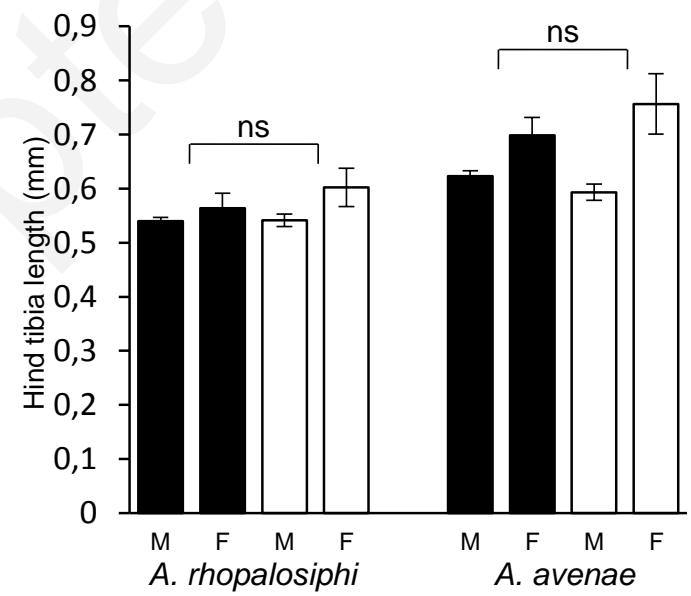


Table 1 Parasitoid and aphid species dominant in winter and spring season

\begin{tabular}{lll}
\hline & Winter & Spring \\
\hline \hline Parasitoids & Aphidius matricariae & Aphidius avenae \\
& Aphidius rhopalosiphi & A. rhopalosiphi \\
Aphids & Rhopalosiphum padi & Metopolophium dirhodum \\
& Sitobion avenae & S. avenae \\
\hline
\end{tabular}

